\title{
Entrevista con Sabina Berman
}

\section{Emily Hind}

Sabina Berman (n.1956) ganó por primera vez el Premio Nacional de Teatro en 1979 y ya por 1983 lo había recibido dos veces más. También ha merecido el Premio Nacional de Teatro para niños. Sus obras de teatro incluyen Muerte súbita, Yankee, Rompecabezas, El suplicio del placer, Aguila o sol, Entre Villa y una mujer desnuda, En el nombre de Dios, La grieta, Krisis, y Molière. También ha escrito teatro para niños: La maravillosa historia del chiquito Pingüica, El árbol de humo y Caracol y colibrí. Su obra en prosa incluye Un grano de arroz, El principio de la civilización y las novelas La bobe y Amante de lo ajeno. Su poesía se encuentra en la colección Lunas. Actualmente radica en México D.F.

Quisiera preguntarte acerca de los cambios en Muerte súbita. Acabo de ver la obra y no se parece del todo a la obra publicada en Berman. Me pregunto el por qué de los cambios. Por ejemplo, ahora hay un beso entre los dos hombres.

Claro, porque en ensayos de pronto dije "queda muy sutil el asunto que si fueron amantes o no." Y pensé que aumentaba la tensión dramática. Me di cuenta que dramáticamente funcionaban mucho mejor las tensiones si se abría el juego. Son cosas que una aprende en ensayo. La diferencia entre escribir prosa y escribir teatro [es:] hasta que no lo ves, no terminas de comprender la obra de teatro, no tu texto sino la obra de teatro.

Otros cambios incluyen el hecho de que Andrés echa a Gloria de la casa; en la versión publicada es Gloria que se decide ir. Además, ahora Odiseo ha matado al viejito. El final también es distinto.

El final es distinto, sí, porque estrenamos de hecho con el final como está escrito. Entonces lo que entendía el público es que se quedaba muerto. Era muy poco satisfactorio porque lo que yo trataba de decir es que el Ángel de la Destrucción [el personaje Odiseo] es un ángel, o sea, que hay veces 
que destruir es importante para seguir. Igual que un capullo se destruye para convertirse en flor. Una situación social a veces se tiene que destruir para convertirse en otra cosa cuando ya está demasiado empantanada. Entonces se quedaba [Andrés] en el piso y al nivel de la emoción del público, funcionaba mejor que la gente pensara que estaba muerto. Los aplausos eran más altos, pero yo dije "De lo que se trata no está sucediendo." Entonces agregamos esa manera en que se levanta Andrés poco a poco y se va recomponiendo. Cuando llega al quicio, se endereza y sale. Cuando yo le explicaba al actor lo que debía suceder, decía, "Si fuera cine, tendríamos una toma de ti desde arriba bajando las escaleras y cada vez nos iríamos más lejos para verte perder en la ciudad." Entonces, lo de la ciudad es un efecto pero no es esencial a la obra. Lo que sí era esencial es que Andrés se libera.

En una conversación anterior cuando visitaste Penn State [en 1995], otra crítica te estaba regañando por cambiar las obras después de publicarlas. ¿Te arrepientes de haber publicado una obra que sigue en proceso de desarrollo?

No. Yo de niña quería ser pintora. Mi mamá tiene una gran cultura sobre pintura y tenía muchos amigos pintores. A mí me encantaban los talleres de los pintores y los veía trabajar. Los pintores piensan en una obra en términos de serie. Van evolucionando un estilo y llegan a un momento climático y después eso se convierte en otro, pero piensan en su trabajo como una evolución progresiva. Entonces yo lo veo igual. Sé que si estuviera escribiendo una novela no podría, pero cada puesta en escena de hecho es otra puesta; es otra obra. Entonces, ¿por qué no puedo hacerlo? Los músicos en el siglo XIX también iban reescribiendo. Hacían una versión para piano y después una versión para cámara y después una versión para sinfónica.

En cuanto a esa evolución, ¿cómo ves la evolución de tu obra? ¿De El suplicio del placer hasta Molière ves un proceso de desarrollo?

Yo supongo que sí. El suplicio del placer, mi primera obra, era basada en sueños personales, pero pretendía ser presente absoluto. Después yo me fui hacia lo histórico, tomando mis tramas de lo histórico. Mientras estaba toda esa época de las obras históricas, decidí que lo que me faltaba era aprender a escribir historias. Decidí que quería escribir sobre el presente. No para capturar el presente, sino porque era una sensación como uno está escribiendo algo único y mi circunstancia no la tenía otra persona a principios del siglo. Hay una emoción especial de trabajar con lo que no ha sido dicho. Es menos intelectual. Entonces Muerte súbita era mi primer intento y también fue mi primer intento de comedia. Whatever that means, porque mientras 
más escribo comedias más me parece naturalismo. En Molière yo le decía a Antonio [Serrano] el director, "Esto que se podría interpretar como el teatro dentro del teatro, por favor no lo hagas porque para Molière la única diferencia entre la vida con público o sin público es que hay público." La tragedia es el arte más estilizado, más lejano a la realidad. Para mí, la comedia es el género más cercano. Lo que implica nada más la distancia de un público que está viendo cuán pequeños somos finalmente.

¿Por qué te interesa trabajar con la historia en Entre Villa y una mujer desnuda, Krisis $y$ Molière?

Tengo una época, mis primeros no sé si siete años de escribir, en que mis tramas las tomaba de la historia, de fuentes bibliográficas. Esto, aunque suena muy pretensioso, se lo aprendí de Shakespeare. Fui a la casa de Shakespeare cuando era adolescente, Stratford on Avon, y me impresionó mucho el uso de Shakespeare de la historia. Allí están sus libros: Plutarco, los historiadores romanos, los historiadores ya renacentistas, incluso las novelas: Otelo. Y [me impresionó] como con absoluta libertad [Shakespeare] escribe una obra de teatro donde modifica las cosas con las necesidades de la obra de teatro y está escribiendo una metáfora sobre su presente. Las obras de Shakespeare no eran para pasar el rato nada más. Ahora para pasar muy intensamente el rato, implica que Shakespeare las está escribiendo por una inquietud actual, ya sea de su país, sobre todo en sus primeras obras. Ya en sus últimas obras apareció más personal: como la vejez, [por ejemplo en] el Rey Lear. Entonces muchos años estuve meditando [y] en un cierto momento [llegué a estar] muy consciente que quiero hacer eso: quiero buscar historias que tienen que ver con mi actualidad pero dejarlas en el pasado, en el "había una vez." Pero después de una cantidad de obras, sentí mucho la necesidad de dos cosas: la inmediatez de la comedia y la inmediatez de hablar de mi contexto.

Entonces [escribí] Villa, que según yo no es una obra histórica. Lo que estoy usando es un personaje histórico para mostrar el inconsciente colectivo de los personajes, porque el inconsciente colectivo de una sociedad - o el consciente colectivo - pero la mente colectiva es la historia de la misma sociedad. Sabía que quería escribir sobre el machismo y claro no es un proceso tan consciente. Es como meter las manos a la plastilina y empezar a moldear y entonces sucede. Tenía una historia tomada de una vecina muy amiga y resulta que su amante en la vida real es un historiador muy conocido en este país y en el extranjero. Yo lo había estudiado en la universidad y uno de sus principales libros que tuve yo que estudiar me gustó mucho. Incluía 
una gran exaltación de los caudillos de la revolución. Entonces a mí me pareció fascinante que él pensara en la democracia con tal intensidad descartando el cincuenta por ciento de la población. Igual que ellos [los revolucionarios]. En México se hizo la revolución para la igualdad, la fraternidad de los mexicanos y siempre en el mismo campo de batalla las soldaderas eran discriminadas y violadas y a nadie le parecía contradictorio, a nadie. Todavía en la Revolución rusa, sí hay una cierta consciencia de que esa igualdad incluye a las mujeres, que además nunca se concretizó totalmente. No ciertamente en las áreas de poder, pero sí en la vida cotidiana. En la Revolución Mexicana para nada. Eso era una metáfora extrema de la situación actual donde hablamos de la democracia y todo el país se divide entre los que quieren la democracia y los que no la quieren. Los que la quieren siguen sin incluir al cincuenta por ciento de la población.

Hay un marco en Krisis y Entre Villa y una mujer desnuda del presente en donde se inserta Benito Juárez o Pancho Villa, pero en Molière todo está en el pasado. ¿Por qué?

Yo quería hablar sobre la comedia. Ya para entonces llevaba Muerte súbita; Pancho Villa llevaba dos años en cartelera; hicimos una película [de Villa] que nos tardó un año - entonces ya llevaba cuatro años - [luego hice] Krisis; llevaba como seis años de realizar comedias. Entonces yo leía las críticas a la comedia y me empecé a dar cuenta que casualmente era la crítica que yo tenía inicialmente cuando empecé a escribir. Tenía la crítica inconsciente de que era vulgar y frívolo escribir sobre causar alegría en el público. Ésa es la verdad: la comedia libera, la tragedia oprime. Tiene sus razones de ser, la tragedia. Me llamaba mucho la atención y cada vez me daba más risa, me parecía más cómico eso, de que cuando nos volvemos adultos despreciamos la alegría. Y de pronto, dije "Es una cosa cultural, pero esto no es sólo de México, esto es por lo menos de todo Occidente." Entonces como hobby estuve leyendo mucho y me di cuenta que casi todos los filósofos están de acuerdo que es más prestigioso el sufrimiento. Entonces dije, "Es ya una complicidad universal." Siempre andaba buscando la historia en que concretizar esto que era parte de mi vivencia de todos estos años. Me tardó más del tiempo que yo hubiera querido decidirme escribir sobre Molière. Esperaba poderme encontrar una anécdota mexicana. Es muy peligroso en México escribir sobre un personaje no-mexicano. Sin embargo, era irresistible porque la historia de Molière es tan hermosa. La misma vida de Molière es una ejemplificación compleja sobre el tema de erotismo y del instinto a muerte en nuestra civilización. Molière, si lo lees, habla de eso directamente. Se 
queja amargamente de por qué es tan difícil ser feliz y de por qué es despreciable ser feliz, por qué el contexto no protege esa felicidad sino que lo complica.

En Krisis hay una mezcla de cine y teatro, por el video al principio $y$ por el final del tercer acto cuando caminan en cámara lenta. También en $\mathrm{El}$ árbol de humo [y en Molière], se repite el diálogo. ¿Es consciente esa mezcla de técnicas cinematográficas con las teatrales?

A mí sí, me influyó mucho hacer cine. Cuando hice cine [la película Villa] me di cuenta que estamos desperdiciando muchos recursos exclusivos del teatro [por ejemplo] los apartes [y otras] cosas que no puedes hacer en cinema y que lo abstracto del espacio escénico nos permitía hacer hasta más de lo que puedes hacer en cine. Me eduqué en las obras más sencillas de Carballido, de Leñero, de Beckett, en el teatro minimalista y me encanta, pero soy de otra generación. Entonces, más bien mi intención es otra. No quiero ser minimalista. Fue una decisión incluso en esa versión de Muerte súbita, que vamos a usar toda la gama de recursos. Es el renuncio al minimalismo y al naturalismo. Usar todos los recursos no es tan sencillo de realizar. Si tú ves [en Muerte súbita] no hay un sólo recurso que implique escenografía; es pura actuación. Sólo actuación, o sea, nunca ocupo algo que tenga que ver fuera de la actuación excepto oscuros, que se podrían omitir; bastaría que los actores hicieran como Brecht, nada más cambio de posición en escena y ya. Yo creo que la tecnología más admirable, más asombrosa es el intelecto. Va la gente, se sienta y se apaga la luz y está de acuerdo que vamos a jugar intelectualmente. Aparecen unos señores que obviamente están parados allí y el intelecto acuerda hacer pacto de creer que van a estar en otro lugar. Es maravilloso: el actor se queda quieto, mueve así y dice "cinco años más tarde" y son cinco años más tarde. Yo quisiera hacer cada vez teatro más dependiente nada más del intelecto, del juego intelectual.

¿Por qué escribes teatro para niños, por ejemplo El árbol de humo $y$ El caracol y el colibrí?

Porque me gustan los niños y creo que es un terreno del teatro muy riesgoso. Hay algo que le aprendí a Molière: Molière cuando tenía ya ensayada su obra, llamaba a los hijos de todos los miembros de su compañía. Entonces dejaba que los niños vieran la obra. Si los niños se reían, si los niños entendían de lo que se trataba, pero no que entendían cada palabra, Molière sabía que la obra iba a ir muy bien. O sea, si está expresado en drama, porque "drama" quiere decir acción, [la obra irá bien]. Por ejemplo la escena central de Tartufo es clarísima. Está un hombre, besa a su mujer, se nota que es su esposa, se 
mete debajo de la mesa. La mesa, diría un psicoanalista, es un desplazamiento de la cama, aunque quién sabe dónde sea más importante el matrimonio: a través de la mesa o a través de la cama, pero es un símbolo del matrimonio. Se mete abajo de la mesa y llega el otro que empieza a seducirla y él está oyendo. Es una síntesis perfecta de la obra y claro los niños entienden. Entienden que los adultos dicen cosas complicadísimas, pero es clarísimo lo que está pasando. Hay un robo allí. Por eso hago teatro para los niños. Allí aprendí a esforzarme para lograr eso.

Es un detalle, pero tus personajes toman mucha medicina, droga $y$ alcohol en las obras. ¿Es una manera de expresar que la vida es dolorosa? Si no es aspirina es --

Prozac. Pues, es mi época. Yo veo que todo el mundo se mete una cantidad de cosas. Yo creo que estamos en la época del narcisismo y que la gente está hiper-consciente de cómo se siente. Si tú ves las obras de Shakespeare, sus parámetros para enfrentar la realidad son otros. Ahora, si damos un salto a algo que no seamos nosotros, es en nuestro trabajo. Porque en la vida cotidiana, la gente sigue hablando de yo. La religión en la que yo me crié fue el psicoanálisis. Mi madre es psicoanalista. Entonces yo le digo a mi madre, "Oye mamá, es que debes estar harta del yo." Y me dice, "Por supuesto estoy harta de yo. Es el personaje más obsesivo del planeta Tierra, ¿no?"

Cuando hablábamos en 1995, te pregunté si tenías miedo que por la devaluación la gente ya no iría al teatro. Y tú me dijiste que la gente siempre irá al teatro. ¿Por qué tienes esa confianza?

Creo que hay suficiente gente que piensa que el teatro no es un artículo de lujo. Para eso tiene que ser gente que está por encima de los niveles de supervivencia, pero esto basta. A partir de entonces el teatro puede ser imprescindible. Y hay gente así. Yo soy alguien así.

¿Hay autoras que te influyeron? ¿Mujeres mexicanas?

Rosario Castellanos. Me deslumbró ver cuando tenía 12 años $E l$ eterno femenino. Ver a las mujeres allí arriba, el desparpajo de Rosario. Su tremenda frescura para hablar de lo femenino desde lo femenino. Me influyó muchísimo. Si no hubiera sido escritora yo, de todos modos me hubiera influido. Hay estas autoras que te cambian la vida. Elena Poniatowska también es para mí una autora - autora o autor - imprescindible. Elena Poniatowska ha sido para mí y yo creo que para gran parte de las - ni siquiera diría escritoras - para las mujeres de este país. Ha sido un modelo moral en cuanto a su arte y su presencia en esta sociedad que en ella no están separados. En Elena la 
lees o la oyes hablar, y podría estar en su cocina o en su estudio o frente a mil personas; no hay una doblez. Eso para mí es una de las cosas que las mujeres podemos agregar a la cultura. Llevar lo privado a lo público, lo público a lo privado, o sea crear un continuo. Cuando conocí a Elena, habré tenido yo 20 años. Fui a llevarle mis poemas y que me haya recibido Elena es ya increíble. Me recibió en su casa y le iba leyendo los poemas y ella iba tendiendo las camas, yendo a la cocina a revisar la cena, checando a sus hijos, y así fue la reunión. Elena no interrumpía su intelecto para hacer labores de su hogar. No había división y no tenía la menor vergüenza de ser un ama de casa. Para mí fue un modelo, su actitud. Claro, Elena nació princesa. [Se ríe.] Siendo princesa es mucho más fácil no tener vergüenza. Esther Seligson es también un modelo importante. Me creo privilegiada de, si no de ser alumna de Esther, sí de estar en mi adolescencia muy cerca a Esther. Tenía una fijación con Esther; la seguía porque era así como un modelo viviendo de lo que yo quería hacer. Yo le oí decir cosas que eran cruciales para mí. Por ejemplo, Esther es judía. Yo soy judía. Le oí responder a un crítico israelí que se quejaba de que ella estuviera en México y no emigrara a Israel porque Esther pasaba en aquel entonces la mitad del año en Israel. Y se quejaba de que Esther teniendo un hebreo completamente fluido, escribía en español. Ella dijo, "Sí, pero es que Dios me puso aquí para volver del castellano una lengua sagrada." Me acuerdo de esta frase y además se la creo.

Para concluir, ¿cuáles son tus proyectos futuros?

Estoy trabajando en una adaptación de La Ronda de Arthur Schitzer, llamada 65 contratos para hacer el amor. También contemplo una adaptación para cine de Muerte súbita, mi obra teatral. En este mes [de enero] presentamos al público Mujeres y poder, un libro coescrito con Denise Maerker sobre la relación novedosa y todavía ardua entre las mujeres y el poder.

University of Virginia y México, D.F. (5 de julio 1999 y 4 de enero 2000) 